\title{
Understanding early childhood education and care utilization in Canada: implications for demand and oversight
}

\author{
Petr Varmuza ${ }^{*}\left(\mathbb{D}\right.$, Michal Perlman $^{2}$ and Linda A. White ${ }^{3}$
}

*Correspondence:
petr.varmuza@mail.utoronto.ca
${ }^{1}$ Applied Psychology
and Human Development,
Ontario Institute for Studies
in Education/University
of Toronto, Toronto, Canada
Full list of author information
is available at the end of the
article

*Correspondence: petr.varmuza@mail.utoronto.ca in Education/University article

\begin{abstract}
This study examined early childhood education and care (ECEC) utilization in Canada, focusing on use of unlicensed home child care (HCC) from an equity perspective. Data from the 2011 cycle of the General Social Survey (GSS) were used. Across Canada, parent responses reveal that $16.6 \%$ of children between the age of 12 months and entry to school were in unlicensed HCC. Another $24 \%$ of working parents reported having no regular form of non-parental childcare. Families with higher incomes were more likely to report using center-based care. Conversely, lower-income working parents with lower levels of education were more likely to use unlicensed HCC or report using no non-parental care at all. Comparison of parent responses in Ontario, however, where government estimates for the number of licensed and unlicensed HCC spaces are available, revealed that more parents report that their children are in licensed HCC than is possible. The lack of accurate parental reporting calls into question a key assumption of current regulatory systems, which is that parents are informed consumers of ECEC services. Given that many parents misreport the type of HCC their children use, and the equity concerns raised by the overall utilization patterns we found, we argue that governments need to take a more active role in oversight and support of HCC.
\end{abstract}

Keywords: Childcare utilization, Unlicensed family childcare, Home childcare, Equity

Many young children in Canada spend a substantial proportion of their day being cared for by someone other than their parents (Friendly et al. 2015; Sinha 2014). However, only a small proportion of these children attend center or regulated home-based Early Childhood Education and Care (ECEC) services. The remaining children are in informal care by relatives or unlicensed home child care (HCC), or their parents "make do" without any form of non-parental care.

The types of experiences children have in ECEC services have been shown to impact their development (Burchinal 2018; Burchinal et al. 2015; Côté et al. 2008). This is especially true for children from low-income households for whom high-quality ECEC may serve as a buffer for negative outcomes associated with coming from at risk backgrounds (Bassok et al. 2016; Loeb et al. 2004; Phillips et al. 2017; Weiland and Yoshikawa 2013). However, research suggests that a lot of child care in Canada and the USA is of mixed quality (Brunsek et al. 2017; Japel et al. 2005; Kamerman and Gatenio-Gabel 2007). For 
example, in a recent systematic review, Brunsek et al. (2017), integrated research linking the Early Childhood Environmental Rating Scale and its revised form [ECERS/ECERSR; (Harms et al. 1998)] to child outcomes. They found that the vast majority of the programs in the 73 papers they reviewed were of just above minimal quality with only nine studies reporting average ECERS/ECERS-R scores that were considered "good". Furthermore, as we describe in more detail below, children from low-income families are more likely to be cared for in ECEC contexts that have been found to generally be of lower quality (Pavolini and Van Lancker 2018; Van Lancker and Ghysels 2016), including HCC (Gingras 2012; Goelman et al. 1993; Japel et al. 2005; Kohen et al. 2008). Yet, few studies track ECEC utilization patterns of low-income families in Canada, especially the use of unlicensed home childcare (see Kohen et al. 2008 for a noteworthy exception). In general, beyond national data on licensed center-based and home care spaces (e.g., Friendly et al. (2018)), and a recent Statistics Canada survey (Findlay 2019), very little information is available about arrangements used by Canadian families with young children.

Recent announcements in some provinces such as British Columbia (Government of BC, 2018) about plans to expand licensed ECEC spaces raise concerns about the type and quality of care that will emerge with expansion. Given the infrastructure and financial challenges of creating and operating centers, a substantial portion of this growth will likely occur through licensed home childcare, not center-based care. We argue, therefore, that this is an opportune moment to take stock of the current state of ECEC services available to different types of families in Canada. We begin to close these gaps in this paper using national data from parents surveyed as part of the General Social Survey in 2011 (Statistics Canada 2011).

We chose the GSS as it provides ECEC information for all the children within the family, not just one selected child, as is the case with other Canadian national datasets that ask parents about this topic [e.g., the National surveys such as the National Longitudinal Survey of Children (NLSCY) and Youth and the Survey of Young Canadians (SYC)]. The structure of the questions on the GSS allowed us to classify care into licensed vs. unlicensed. It was then possible to categorize unlicensed care into four subtypes of ECEC based on where such care takes place and who delivers it. Given that in Canada, oversight and regulation of ECEC services is the responsibility of the provinces, to the extent possible using GSS data, we examined regional differences in utilization of such services as well as whether there are regional differences in the types of families who use different types of care.

We find substantial regional differences in ECEC utilization in both levels of access and types of care available to children and families. Furthermore, a significant proportion of full-time working families relied on care by parents alone. Parents with lower incomes, lower levels of education and those who work irregular hours are also more likely to use unlicensed home child care compared to higher-income, better educated parents, who work regular hours.

\section{Background}

Existing evidence from across a number of OECD countries reveals quite varied patterns in child care usage. Higher-income families have access to more regulated forms, and generally better quality ECEC services, while the most disadvantaged segments of 
the population use lower quality ECEC arrangements (Debacker 2008; Pavolini and Van Lancker 2018; Porter et al. 2010; Raikes et al. 2005; Torquati et al. 2011; Van Lancker and Ghysels 2016). Researchers in British Columbia (BC) (Goelman and Pence 1988) found that level of family resources was highly correlated with the quality of ECEC services parents secure for their children. Furthermore, families in higher-income neighborhoods (Cloney et al. 2016; Malik and Hamm 2017) have access to higher-quality programs. These usage patterns raise important equity concerns since the most compelling evidence about the impact of ECEC quality on children suggests that children from disadvantaged backgrounds are the ones who are most likely to benefit from receiving highquality care (Magnuson et al. 2007; McCartney et al. 2007). Thus, while high-quality ECEC services can serve as a protective buffer for low-income children (Weiland and Yoshikawa 2013), it appears that it is precisely the children who need it most who are least likely to receive high-quality care.

Numerous studies highlight the severe shortage of ECEC services throughout much of Canada, with regulated spaces available for only $27 \%$ of Canada's approximately 4.9 million children aged $0-12$ and $29 \%$ of children aged $0-5$ as of 2016 (Friendly et al. 2018, p. 146). Even parents who can afford center-based care may not be able to secure it because of lack of availability. For many low- and middle-income families, the cost of care presents a significant barrier that frequently is overcome only using relatively cheaper, unlicensed HCC- or no non-parental care at all. This is problematic as it pushes lower-income parents into care that has been found to be of lower quality. For example, Goelman and Pence (1988) found that licensed HCC providers tend to be of higher quality when compared to unlicensed HCC. Findings from Quebec (Japel et al. 2005; Bigras et al. 2010) suggest that quality of center-based programs generally exceeds that of HCC (Laurin et al. 2015). Finally, quality scores have also been found to be much more variable in both licensed and unlicensed HCC than it is in centers (Goelman and Pence 1988). Thus, it is important to explore whether type of care is distributed equitably across families with different demographic characteristics.

For all these reasons, this article focuses on the unlicensed portion of the ECEC sector. By unlicensed we mean care by a non-relative (which we label "care by stranger") that is provided outside the child's home (which we label "elsewhere"), typically in a provider's home. We intentionally steer away from using the term family childcare to describe this form of care because "family" mischaracterizes the market relationship that exists in the business transaction between parents who pay providers and who are running a small business, to look after their children in a group setting. Instead, we use the term home childcare (HCC) and make further distinctions with respect to the license status when necessary. It is important to note, however, that there is substantial variability in the terms used in surveys and in the policy and regulatory language used across provinces and territories. Government reports and other policy documents refer to home childcare in Ontario; family childcare in Manitoba; community day care home in New Brunswick; and family day home in Alberta. The use of inconsistent language provides a methodological challenge in national surveys including the GSS that use a single term when asking parents about childcare utilization across the country.

We are particularly interested in learning more about parental use of unlicensed $\mathrm{HCC}$, for a number of reasons. First, within the Canadian context, very little is 
known about unlicensed HCC; however, as noted above, research in other jurisdictions has found that unlicensed care is of lower quality than licensed services (Bassok et al. 2016). And while there is, undoubtedly, a range of quality in all care, including unlicensed HCC operating outside provincial licensing frameworks, we also observe examples of egregious safety violations occurring in unlicensed settings. For example, in 2014 alone, as the Ontario government was in the process of modernizing its childcare act, four infants and toddlers died of unnatural causes in unlicensed HCC (Ontario Ombudsman 2014). Yet, the government proceeded to update provincial child care legislation and regulations without requiring an individual licensing scheme which even the independent child care providers supported (White et al. 2018).

In the Canadian context, since the National Childcare Study carried out in 1998 (Goelman et al. 1993), large-scale studies of unlicensed HCC have been rare. Local studies, be they on municipal or provincial provision, are very rare as well with some notable exceptions including Goelman and Pence (1988). Only in the province of Quebec are there government-funded studies evaluating ECEC in a variety of settings (Japel et al. 2005). Most studies utilizing the NLSCY and SYC either categorize center-based and licensed HCC under the "regulated" category (Cleveland et al. 2008; Kohen et al. 2008) without differentiating between the two types of care, or make a general distinction between center-based and HCC services (Cleveland et al. 2008; Haeck et al. 2015; Lefebvre et al. 2012; Lehrer et al. 2015) without differentiating based on licensing status.

One reason for the absence of information about unlicensed HCC is precisely because it is unlicensed: there are no records of unlicensed providers operating across the country making it very difficult to study such care. As a result, we know virtually nothing about even the most basic facts such as their number and the number of children they serve. Furthermore, beyond limiting the ages and number of children that a caregiver can care for, unlicensed HCC is unregulated and unmonitored, with exception of a health and safety complaint that would trigger a provincial official's visit.

It is also worth noting that in Ontario, as is the case in Alberta, Nova Scotia, Quebec and parts of Newfoundland and Labrador, the only way a HCC provider can become licensed is by joining an agency. Individual licensing is not available to HCC providers in those jurisdictions. The agency is licensed by the province and, in exchange for a non-trivial daily per-child fee, provides oversight and support that ranges from referral and billing services to regular home visits. Provincial oversight may be limited to licensing visits to agency headquarters and an inspection of a small number of homes.

This lack of oversight of unlicensed HCC is in stark contrast to the highly regulated childcare centers and licensed HCC providers that experience strict provincial oversight regimes including regular monitoring that can also include additional site visits from municipal bodies such as public health agencies. Thus, ECEC regulation is bifurcated, with much of the sector being highly regulated, but with a portion of HCC providers permitted to operate legally with virtually no regulations and oversight (Perlman et al. 2017; White et al. 2018).

Other forms of childcare, including care provided by a relative, be it the child's home or in some other place, fall outside all provincial regulatory frameworks as long 
as no unrelated children are present. Care by a nanny in the child's home is similarly unregulated, although the relationship between the nanny and parent/employer is covered under provincial labor laws.

The presumption behind the very loose regulation of unlicensed $\mathrm{HCC}$ is that parents are savvy consumers of childcare services (see White et al. 2018). However, research demonstrates that, at best, parents are constrained consumers of ECEC services. Specifically, parents' choices are constrained by cost (relative to parental income), location, availability, and scheduling (Forry et al. 2014; Sandstrom and Chaudry 2012). While some research has found that parents can accurately assess the characteristics of care arrangements for their children (Gamble et al. 2009; Lehrer et al. 2015), other research has found that parents have incomplete or inaccurate knowledge of their child's care experience (Howe et al. 2013; Mocan 2007). Other research demonstrates that parents' decision to use unlicensed HCC may not be related to quality as much as to other factors such as availability, cost and convenience. Gable and Halliburton (2003) report that in general, parents tend to choose HCC because they provide "a personal relationship with a consistent caregiver, and warm, individualized care in a home setting" (see also Kontos et al. 1995). In contrast, parents tend to choose centers because they are perceived as more educational (Gable and Halliburton 2003). Finally, Han (2004) finds a dynamic two-way relationship between work schedules and type of care. Parents tend to revert to regulated ECEC arrangements when their work schedules allow. This suggests that many parents use informal care as a last resort, rather than as a preferred child care choice, especially for preschool children. It is also worth noting that the whole discussion of parent "choice" is moot in places where there is a scarcity of child care and parents may simply take the first viable option available to them.

Economic research characterizes the ECEC market as one of the asymmetric information (Blau 2007; Mocan 2007) where parents are the purchasers of services but their children are the recipients. For markets to regulate quality and ensure minimum health and safety, consumers of these services must have full information so that they can comprehensively weigh both cost and quality in choosing between care providers. Research has found that parents have difficulty in comprehensively assessing risk for services they themselves do not receive (Blank 2000). As noted above, parents often have gaps in their knowledge about their child's ECEC services (Howe et al. 2013). Asymmetries in information make it difficult for parents to accurately assess quality as they may not know what qualities to look for in a provider. They also may not have the time or be permitted to closely monitor the ECEC staff or premises (Walker 1992) and they may not know whether their provider is licensed or whether the premises meet basic health and safety standards.

Although licensing status of HCC has sometimes been taken as a proxy for program quality, research reveals that parents often fail to accurately describe the licensing status of their childcare provider (Davis et al. 2014). In 2013, amid a rash of incidents in licensed and unlicensed ECEC programs, the Canadian Broadcasting Corporation (CBC 2013) reported the results of an online survey of 1000 Canadian families by Legere Marketing in which $74 \%$ of parents understood that their ECEC arrangement was licensed by the provincial government. Although the $\mathrm{CBC}$ survey was not methodologically rigorous (for example, like much of the research in this area, the sample is not representative), 
it is clear that survey respondents vastly overstated the proportion of ECEC providers that was licensed under various provincial regulations. Even provincial governments may have difficulty in estimating different usage patterns. For example, in the 2017 Early Learning and Childcare Agreement between the Government of Canada and the Province of Ontario, the Ontario Ministry of Education estimated that about 30,000 children of all ages are in licensed HCC (Canada 2017, Annex 2). However, based on the Ministry of Education surveys of licensed child care operators conducted in 2015 and 2017, the numbers appear to be significantly lower. To our knowledge, such estimates are only available in Ontario.

To develop more appropriate policies and to inform future research, it is clear that more data are needed about ECEC utilization across the country, as well as the equity of access to ECEC services for families with different demographic characteristics. In keeping with these needs, the goals of this study were to examine: (1) ECEC utilization in Canada with a particular interest in national use of unlicensed HCC; (2) ECEC utilization in Canada from an equity perspective with the expectation that children from lower income, less educated families would be more likely to be cared for in unlicensed HCC; (3) regional differences in ECEC utilization in different regions across Canada; and finally (4) differences in government estimates, based on sector surveys, of the number of spaces in licensed HCC with the number of parents who report that their children are in such care in the GSS. Since government estimates are only available for Ontario, we also present GSS data on this topic for Ontario.

\section{Methods}

\section{Data}

To begin to answer these questions, we examine data from the General Social Survey (GSS). ${ }^{1}$ The GSS is an annual cross-sectional stratified survey of 25,000 individuals in ten provinces that focuses on a different social issue every year. We used Cycle 25 collected over a 10-month period in 2011 because it focused on ECEC services. GSS data collection took place between February 1st and November 30th of 2011. We used the "analytical" data file through the Statistics Canada Research Data Centre (RDC). All processing of the raw data was done in the RDC located at the University of Toronto. RDC staff vetted exported tables to ensure that minimum cell size criteria for protection of individual information were met.

For the purpose of this study, we have selected families based on the presence of children who were not yet in school. We focused on children prior to school entry because these children and families are likely to need ECEC services. Provinces differ in cut-off dates for eligibility or the requirement to begin Grade 1 . As a result, to identify children who had not yet started school across the country, each child's inclusion in the survey frame had to be individually calculated. Because we were interested in the ECEC choices of parents who were likely to be in the work force and many Canadian mothers (and some fathers) take advantage of Canada's parental leave policies, we focused on children who were a year or older. Our final sample consists of approximately 1100

A detailed description of the methodology and the questionnaire for the GSS Cycle 25 can be found at the Statistic Canada website: http://odesi1.scholarsportal.info/documentation/GSS25/c25_userguide_eng.pdf. 
family records; after the application of household weights, our sub-sample represents 1.44 million families with 2.18 million children over the age of 12 months at the date of the survey.

The following variables were used or created from items in the GSS. ECEC arrangement information was categorized from different questions that tapped into type of care (center, licensed home childcare, care by non-relative and care by relative including a sibling); who provided care; where the care took place; and the relationship of the respondent to the care giver. This resulted in seven categories of care: center-based; licensed home childcare; care by a stranger in child's home (i.e., nannies); care by a relative in the child's home; care by a relative outside child's home; care by a stranger outside of the child's home (i.e., HCC); and no care.

Other extracted or calculated variables included geographic location where individuals lived, family status (single or two-parent), full-time working status (30 or more work hours per week), whether parents worked "regular" work hours, and individual education and income for parents as reported by the respondent. Parent income was dichotomized into above and below the median for the province in which the family lived. Individual provincial income medians were used rather than one national median to account for income variability across Canada. Parents' work schedules were categorized as regular (Monday to Friday, 9 a.m. to 5 p.m.) or irregular. Respondent education was categorized as: (1) some university; (2) some college/trade school; and (3) some high school or other. We used information for all children in the family.

\section{Missing data}

The missing data rate was low in our sub-sample of the GSS (for example, the rate for education was .74\%). The only variable for which it was necessary to impute data was family income. In that case, a two-step procedure was used: when total household income data were missing, the answer to survey questions identifying individual income categories for the respondent and the spouse (when present) was used to provide a basis for the assignment into the above or below median categories. When all of the income variables were missing, data were imputed on the basis of probabilities of belonging to either category computed from the education, and working status of the families in the given province.

\section{Data analysis}

Data processing and analysis was conducted in Stata 15 (Stata Statistical Software: Release 15 2017). Each table from the GSS was generated three times, first, to ensure that the individual cell counts met the Statistics Canada minimum requirement of five units in a cell. In a second step, household weights provided for each record were applied. Lastly, a "svy:tabulate" module was run to provide coefficients of variation to determine the reliability of the data within individual cells.

The results presented in this article are primarily descriptive. In many cases, we present percentage distributions rather than actual numerical estimates to emphasize the focus on the distributional characteristics of individual types of care and families who are using it. We also show odds ratios with 95\% confidence intervals to identify effect 
sizes when illustrating a particular characteristic of interest within individual figures and tables.

To test differences in family characteristics by type of care used, we ran three multinomial regression analyses. In the first, we compared the family characteristics of parents who reported having no care at all with those of parents who reported using either licensed or any form of unlicensed care including care by nannies and relatives. In the second analysis, the outcome variable was nominal with four categories as follows: licensed center-based, licensed HHC; unlicensed care, and no care.

When child care centers (which in Canada are always licensed) and licensed HCC are grouped together, we refer to this grouping as the "licensed" sector; the "unlicensed" sector is comprised of all other care delivered within private home settings. Not using any care was used as a reference in both sets of analyses. The independent variables included in all models were number of preschool aged children in the family, family income level compared to a provincial median, full-time work status, combined level of family educational attainment, and age of the youngest non-infant child. We use results from these analyses to identify the contribution of the individual variables to the type of care used.

In each model, we show a Relative Risk Ratio (RRR) which can be interpreted as the percentage that the outcome-that is, the type of care of interest-is more or less likely to occur compared to the base outcome of not using any child care if all the other variables are held constant. For ease of interpretation, we use the terms "odds ratio" and "likelihood" rather than "Relative Risk Ratio".

Our analysis first describes child care usage across Canada. We then explore some of the family characteristics associated with using different types of care to address our equity in ECEC utilization question. Whenever possible without transgressing Statistics Canada's confidentiality restrictions and reliability guidelines, we then replicate the same analyses on a regional level. Regions are defined as follows: the four Atlantic provinces; Quebec; Ontario; the Prairie provinces and BC. In reporting the regional-level data, we use overall patterns for Canada as a comparison. In addition, we present the data for Canada without Quebec since availability, cost and usage rates are dramatically different in that province compared to the Rest of Canada (ROC). Finally, we present data for Ontario only to allow us to compare use of unlicensed HCC as reported in the GSS for that province to estimates based on Ontario government surveys.

\section{Results}

Part I-Utilization across Canada

Figure 1a, b describes utilization patterns across the country for children from all families and for children from families in which all parents work full-time.

Figure 1a tracks ECEC utilization for all Canadian families with children who are older than 12 months but have not yet enrolled in the formal schooling in their province. All children are included regardless of their parents' work status. The majority of children $(54.4 \%)$ across the country are in some form of ECEC. Parents report that nearly twice the number of children are in licensed compared to unlicensed care. Among the four types of unlicensed $\mathrm{HCC}$, care by a stranger outside the child's home is the most 


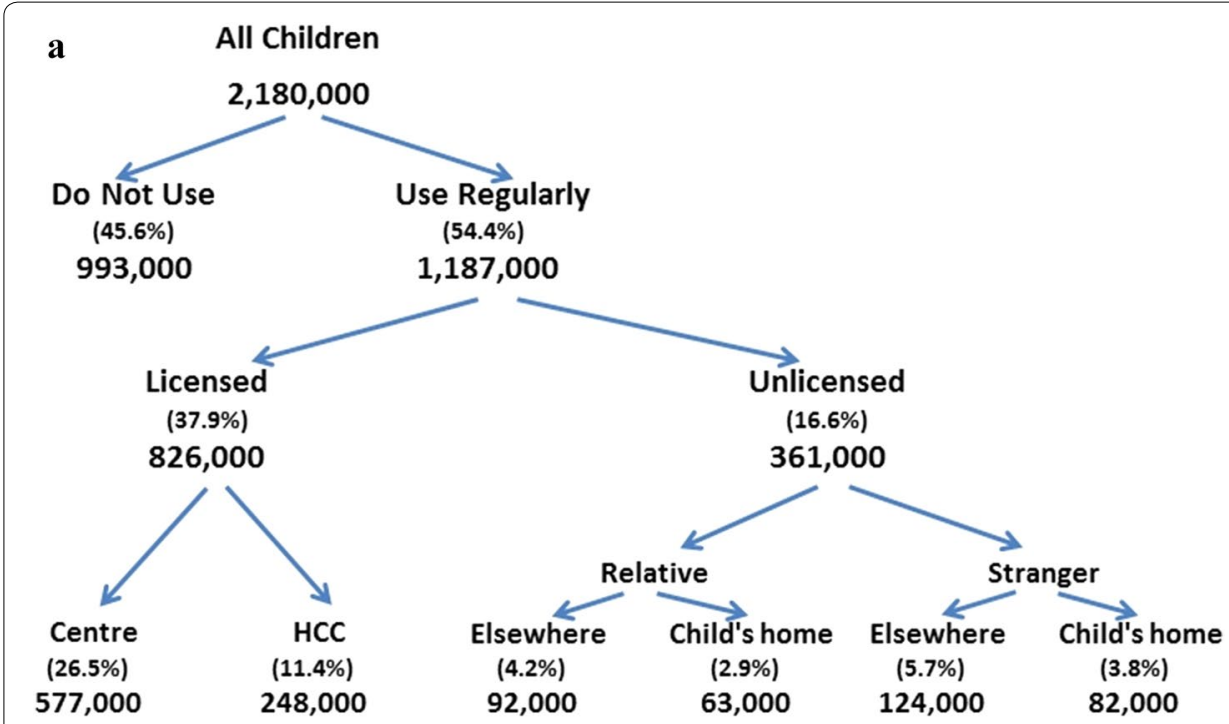

Note: Totals may not add up due to rounding to the nearest 1,000 at each level; percentages have been calculated from raw data

\section{b Children in Full-time Working Families}
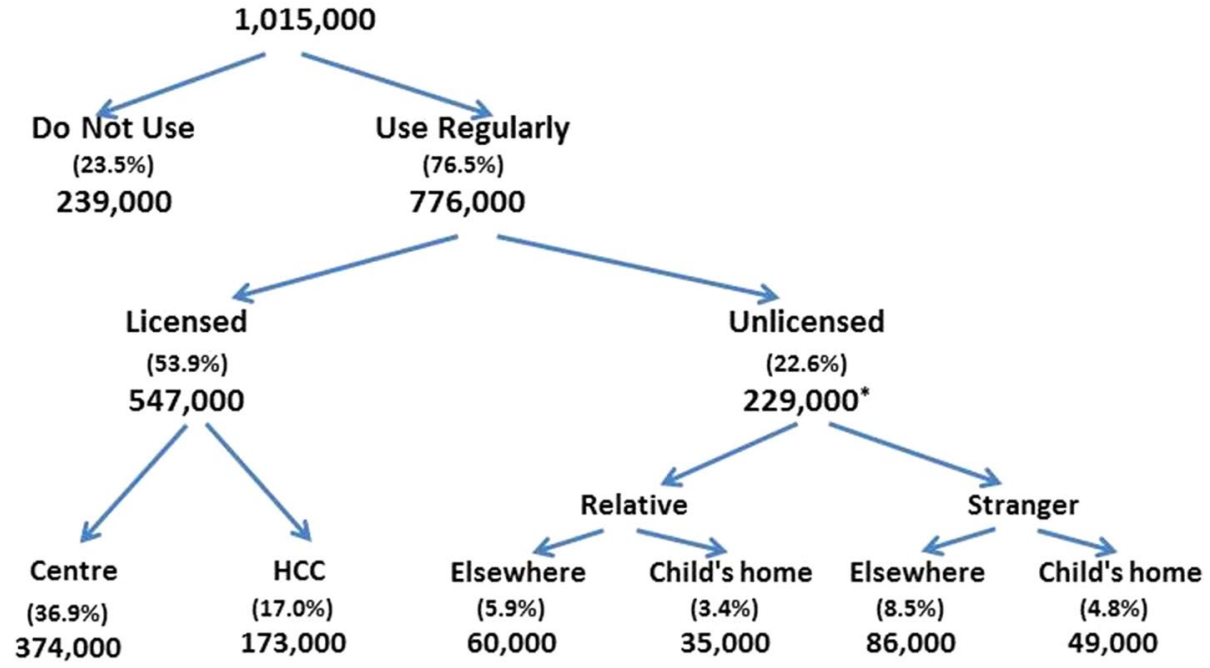

Note: Totals may not add up due to rounding to the nearest 1,000 at each level; percentages have been calculated from raw data Fig. 1 a Early childhood education and care usage for children aged 12 months to school entry. b ECEC usage for children with full-time working parents

prevalent with parents reporting that 124,000 children $(34.3 \%$ of all types of care that is not licensed) across the country receive such care.

Figure 1b focuses on children whose parents worked full-time. Not surprisingly, a much higher proportion (76.5\%) of children from working families attends ECEC services on a regular basis. Nearly one quarter (23.5\%) of children below the age of school entry whose parents work 30 or more hours per week do not access regular non-parental care. 
Table 1 Type of ECEC used by the youngest child in the family

\begin{tabular}{|c|c|c|c|c|c|c|}
\hline \multirow[t]{3}{*}{ Type of care } & \multirow{2}{*}{\multicolumn{2}{|c|}{$\begin{array}{l}\text { Model } 1 \\
\text { All families } \\
(N=1810)\end{array}$}} & \multirow{2}{*}{\multicolumn{2}{|c|}{$\frac{\text { Model } 2}{\text { All families }(N=1810)}$}} & \multirow{2}{*}{\multicolumn{2}{|c|}{$\begin{array}{l}\text { Model } 3 \\
\text { Full-time working } \\
(N=915)\end{array}$}} \\
\hline & & & & & & \\
\hline & Odds ratio & SE & Odds ratio & SE & Odds ratio & SE \\
\hline \multicolumn{7}{|l|}{ Licensed (center and home) } \\
\hline \# of children under age 6 & $.704^{* *}$ & .094 & & & & \\
\hline Income above median & $1.538^{* *}$ & .221 & & & & \\
\hline Full-time working & $5.843^{* * *}$ & .798 & & & & \\
\hline Family education & $.890^{* * *}$ & .022 & & & & \\
\hline Age of youngest child (years) & .983 & .046 & & & & \\
\hline \multicolumn{7}{|l|}{ Center-based } \\
\hline \# of children under age 6 & & & .849 & .125 & .781 & .184 \\
\hline Income above median & & & $1.595^{* *}$ & .250 & $2.480^{* * *}$ & .592 \\
\hline Full-time working & & & $5.736^{* * *}$ & .862 & 1.000 & (Omitted) \\
\hline Family education & & & $.878^{* * *}$ & .024 & $.870^{* *}$ & .038 \\
\hline Age of youngest child (years) & & & $1.111^{*}$ & .057 & 1.055 & .085 \\
\hline \multicolumn{7}{|l|}{ HCC (licensed) } \\
\hline \# of children under age 6 & & & $.494^{* * *}$ & .099 & $.542^{*}$ & .148 \\
\hline Income above median & & & 1.421 & .294 & $2.30^{* *}$ & .651 \\
\hline Full-time working & & & $6.160^{* * *}$ & 1.212 & 1.000 & (Omitted) \\
\hline Family education & & & $.915^{*}$ & .033 & .932 & .044 \\
\hline Age of youngest child (years) & & & $.756^{* * *}$ & .047 & $.750^{* *}$ & .070 \\
\hline \multicolumn{7}{|l|}{ Unlicensed care } \\
\hline \# of children under age 6 & .920 & .137 & .921 & .138 & .751 & .171 \\
\hline Income above median & $1.442^{*}$ & .241 & $1.441^{*}$ & .240 & $1.844^{*}$ & .439 \\
\hline Full-time working & $5.593^{* * *}$ & .942 & $5.591^{* * *}$ & .942 & 1.000 & (Omitted) \\
\hline Family education & .948 & .027 & .948 & .027 & .963 & .042 \\
\hline Age of youngest child (years) & 1.047 & .062 & 1.048 & .063 & .990 & .084 \\
\hline Not using any child care & \multicolumn{6}{|c|}{ (Base outcome) } \\
\hline
\end{tabular}

Family education is a composite variable where lower values represent higher educational achievement for both parents Income above median is a dummy variable where "1" represents income above the median income of families with children above 12 months old and below the age of entry to Grade 1

Odds ratios are interpreted as follows: value above 1.000 represents a percentage that the outcome is more likely for that particular group compared to the base outcome, assuming that all other variables are held constant. Conversely, a value below 1.00 represents a less likely outcome

Unlicensed care includes care by a relative outside the child's home, care by a relative in the child's home, care by a stranger outside the child's home and care by a stranger in the child's home

${ }^{*} p<.05,{ }^{* *} p<.01,{ }^{* * *} p<.001$

\section{Part II-Who uses what type of care across Canada}

Table 1 provides the results of three multinomial regressions. The first, Model 1, compares family characteristics of parents who report that their children experience no regular form of care to characteristics of parents who report that their children attend licensed or unlicensed care. Model 2 presents results from parsing the licensed care sector into center-based and HCC. Finally, Model 3 replicates the Model 2 for a sample constrained to full-time working families only.

In Model 1, with the exception of the higher odds of being employed and having incomes above their provincial median, the users of unlicensed care are strikingly similar to families who do not use any child care. The comparison of users of licensed care to families who report using no care at all reveals significant differences in all variables with 
the exception of the age of the youngest child. These differences include having fewer children under the age of six and significantly higher education attainment for users of licensed care.

Results for Model 2 indicate that parent education is associated with higher odds of using either form of licensed care (i.e., center-based and HCC). Parent education does not predict use of unlicensed care vs. no care at all. Families with more children under age six are less likely to use licensed HCC compared to using no care at all. The number of children under age six did not predict center or unlicensed care compared to no care at all. Families in which the youngest child was closer to school entry had higher odds of using center care compared to no-care at all. In contrast, having a relatively younger child was associated with higher odds of being in licensed HCC compared to having nocare at all. Finally, higher income was predictive of using both center care and unlicensed care compared to no care at all. Income did not increase the odds of being in licensed HCC compared to no care at all.

Overall, the pattern of results is similar for the sub-sample of working families presented in Model 3. One exception is that parent education was not a significant predicator of use of $\mathrm{HCC}$ vs. no care at all; conversely, higher levels of educational achievement increase the likelihood of using center-based care.

A closer examination of Table 1 reveals relatively large standard errors for the dummy variable of 'Income above median'. These high-standard errors might reflect the fact that many low-income families in Canada have access to child care subsidies. However, because every province has different financial eligibility criteria and also controls the amount of subsidy funding, it is difficult to identify the contribution of subsidies to the large standard errors and confidence intervals.

In a supplementary analysis, we investigated the ECEC usage of full-time working families classified according to their work schedules. Whenever at least one parent typically worked shifts other than the usual Monday-Friday during day-time hours, the family was classified as having irregular work schedule; $42.3 \%$ of children were in families in which one or both parents worked non-standard work schedules.

As shown in Fig. 2, we find that children in families with standard work schedules used center-based care with a higher frequency $(\mathrm{OR}=1.7095 \% \mathrm{CI}[1.69,1.71])$, while experiencing lower levels of not having any non-parental care. Children in families with nonstandard schedules were more likely to be in unlicensed care $(\mathrm{OR}=1.35,95 \% \mathrm{CI}[1.34$, $1.37])$ or receive parental care only $(\mathrm{OR}=1.43,95 \% \mathrm{CI}[1.41,1.44])$.

The heterogeneity of incomes is also reflected within the unlicensed sector. Figure 3 shows that lower-income families are over represented in the care by a relative outside the child's home category at $62 \%(\mathrm{OR}=2.17,95 \% \mathrm{CI}[2.13,2.20])$, while families who use nannies - care by a stranger in the child's own home-are found primarily in the higherincome category at $68 \%(\mathrm{OR}=2.37,95 \% \mathrm{CI}[2.33,2.45])$.

For unlicensed care by a stranger outside the child's home, the proportions of lowerand higher-income families are relatively close ( $47 \%$ vs. $53 \%)$. Not surprisingly, when we compare care by a relative (regardless of whether it takes place in child's home or elsewhere) and care by a stranger (regardless of whether it takes place in child's home or elsewhere), the odds are almost twice as high of care by a stranger being provided to children from more affluent families than children from less affluent families $(\mathrm{OR}=1.93$, 

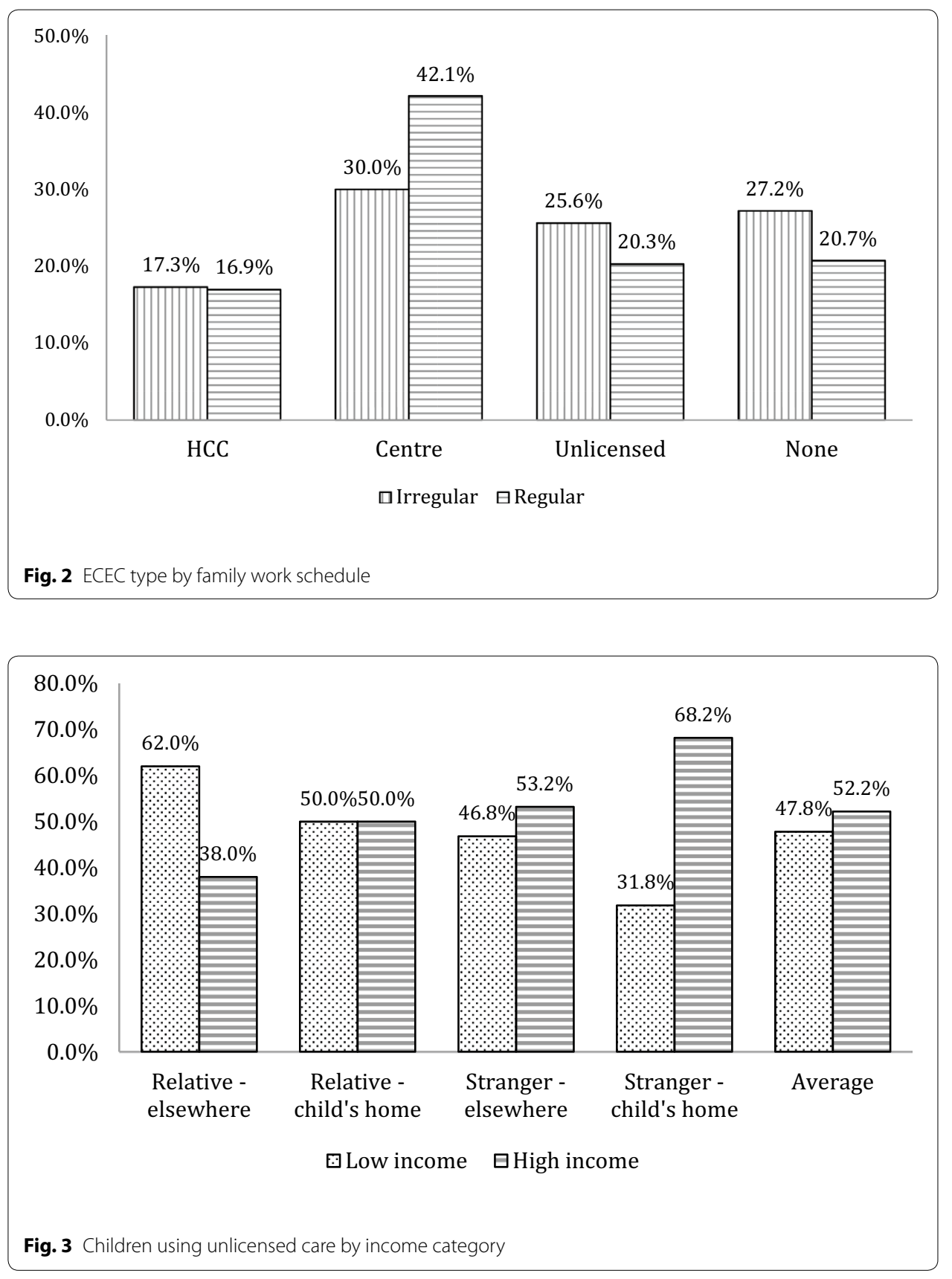

$95 \%$ CI $[1.91,1.96])$. Notably, the proportion of children in the category of care by stranger outside the child's home is similar for both income groups (Fig. 3).

\section{Part III-ECEC utilization across Canadian regions}

It is worth noting that because approximately $37 \%$ of children in our sample reside in Ontario, the general pattern is that Ontario's statistics are similar to the rates in ROC and the Country as a whole. The proportion of parents who reported using ECEC services on a regular basis varies across the regions of Canada. As shown in Table 2, it ranges from $44 \%$ of children in the Prairie region to a high of $71 \%$ in Quebec. 
Table 2 Patterns of ECEC utilization across the regions of Canada

\begin{tabular}{|c|c|c|c|c|c|c|c|}
\hline & Atlantic (\%) & Quebec (\%) & Ontario (\%) & Prairies (\%) & B.C. (\%) & Canada (\%) & ROC (\%) \\
\hline \multicolumn{8}{|l|}{ ECEC utilization } \\
\hline Licensed & 39 & 62 & 35 & 22 & 24 & 37 & 30 \\
\hline Unlicensed & 24 & 9 & 18 & 22 & 21 & 17 & 20 \\
\hline None & 38 & 29 & 48 & 56 & 56 & 49 & 51 \\
\hline \multicolumn{8}{|c|}{ Full-time working } \\
\hline Licensed & 48 & 73 & 38 & 39 & 31 & 49 & 38 \\
\hline Unlicensed & 31 & 8 & 40 & 34 & 32 & 28 & 36 \\
\hline None & 21 & 19 & 22 & 27 & 37 & 24 & 25 \\
\hline \multicolumn{8}{|c|}{ In care $30+$ hours } \\
\hline Licensed & 54 & 69 & 53 & 62 & 44 & 60 & 53 \\
\hline Unlicensed & 52 & 64 & 49 & 46 & 50 & 51 & 49 \\
\hline \multicolumn{8}{|c|}{ Unlicensed HCC provided by } \\
\hline Relative & 36 & 18 & 32 & 28 & 33 & 30 & 31 \\
\hline Stranger & 64 & 82 & 68 & 72 & 67 & 70 & 69 \\
\hline \multicolumn{8}{|c|}{ Unlicensed HCC place of care } \\
\hline Child's home & 36 & 11 & 42 & 39 & 51 & 39 & 42 \\
\hline Elsewhere & 64 & 89 & 58 & 61 & 49 & 61 & 58 \\
\hline
\end{tabular}

Excluding usage in Quebec, the average use of ECEC in the rest of Canada (ROC) is $50 \%$. There is large gap between Quebec and the rest of the country in the proportion of children who are in some form of licensed care (OR $=4.32$, 95\% CI $[4.28,4.36])$. The country percentage of children in licensed care drops by almost eight points if Quebec's contribution is removed. However, even after accounting for Quebec's unique usage patterns, Table 2 shows that, across the country, more children attend licensed than unlicensed care. At the same time, the reported rates of accessing licensed care are significantly higher in the eastern part of the country than in the Prairie region or BC. In Western Canada, the rates of licensed and unlicensed care are very similar.

Turning to ECEC usage by children with full-time working parents, we noted earlier that, across Canada, $24 \%$ of children in families with full-time working parents are cared for by their parent(s) only. British Columbia stands out with the highest percentage of children exclusively in care by parents; at $37 \%$ the odds of not having any non-parental care are more than twice as high as in the rest of the country $(\mathrm{OR}=2.08,95 \% \mathrm{CI}[2.05$, 2.11]). However, even in Quebec, almost one-fifth of children with full-time working parents are cared for by their parents only.

The majority of children using ECEC services on a regular basis spend more than $30 \mathrm{~h}$ per week in care. Children in Quebec spend the most hours in both licensed and unlicensed care. Removing Quebec's usage reduces the percentage of children spending more than $30 \mathrm{~h}$ per week in child care from $60 \%$ for licensed care and $51 \%$ for unlicensed care to $53 \%$ and $49 \%$, respectively. BC is the only region where the reported proportion of children with 30 or more hours in care is higher in the unlicensed sector.

As seen from the Fig. 4 and Table 2, unlicensed care is a significant component of the ECEC landscape across the country. The two lower sections of Table 2 provide a regional look at the composition of the unlicensed sector by focusing on who provides care and where the care takes place. Statistics Canada's data confidentiality restrictions and 


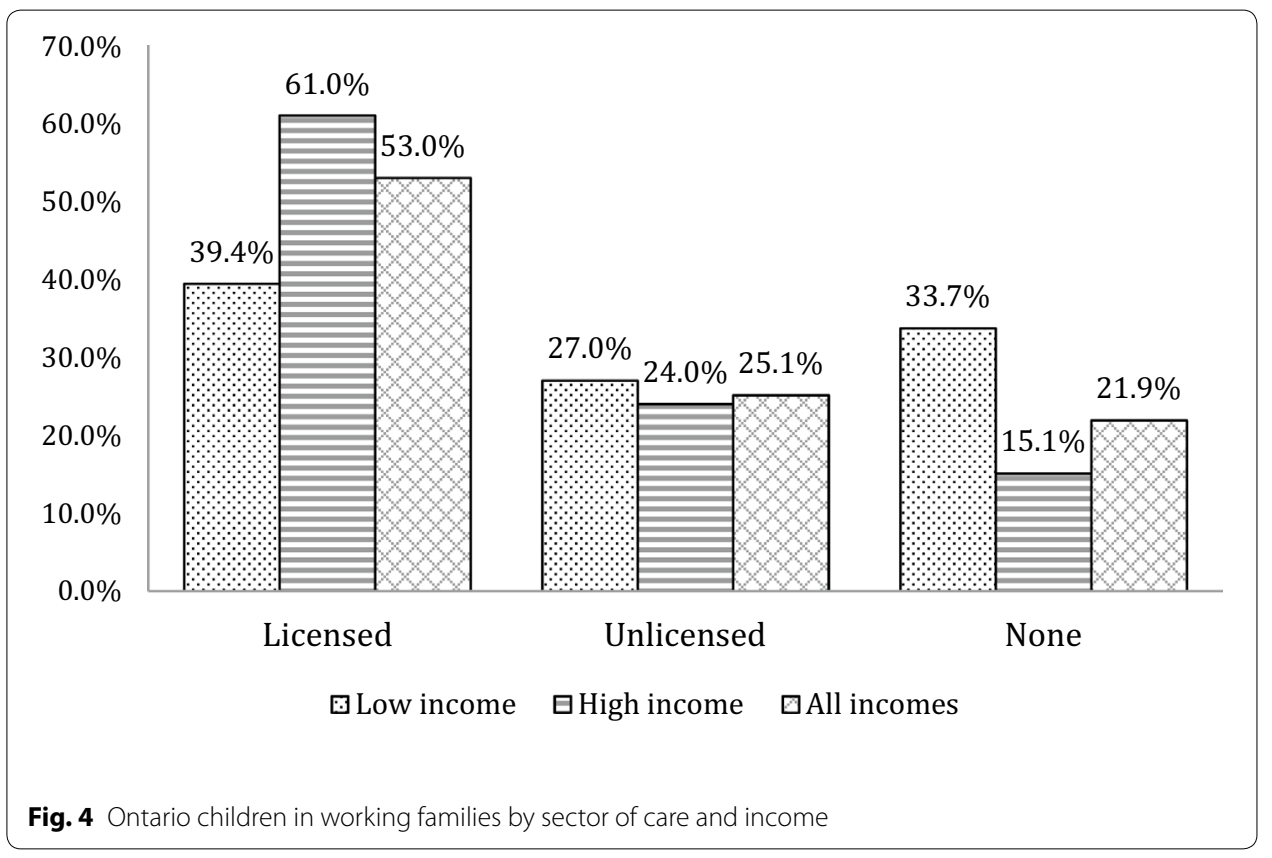

reporting guidelines prevent us from presenting the four categories of unlicensed child care identified in Fig. 1a, b for the individual regions. They also require us to present the data for children from all families, regardless of their parents' work status. Instead, the data have been aggregated according to who provides the care (a relative or a stranger), and where care takes place (in the child's home or elsewhere).

Care by a stranger (non-relative) is the most frequently used type of care in every region of Canada (70\%), with the largest share occurring in Quebec (82\%) and lowest in Atlantic Canada (64\%). While most of the care is provided outside the child's home, in Quebec the odds of unlicensed care being provided outside the child's home are 6 times more likely than in rest of the country $(\mathrm{OR}=6.13,95 \% \mathrm{CI}[5.95,6.32])$. On the other side of the spectrum is $\mathrm{BC}$ where the proportions of ECEC in and outside of child's home are very similar.

\section{Part IV—ECEC utilization in Ontario}

In 2011 GSS parents reported (Table 3) that 51\% of Ontario's children who attend some type of child care are in center-based care. Fifteen percent of children are in licensed HCC and another $10 \%$ are in unlicensed HCC, thus a total of $25 \%$ of children attend some form of HCC. The remaining $23 \%$ of children are in some other form of unlicensed care including care by a relative or care by a nanny.

Working parents with lower incomes in Ontario are far more likely to report having no regular form of child care compared to their higher-income counterparts ( $\mathrm{OR}=2.73$ $95 \%$ CI $[2.69,2.77])$. They are also less than half as likely to report that their children are in licensed care $(\mathrm{OR}=.44,95 \% \mathrm{CI}[.44, .44])$. At the same time, the rates of unlicensed care are somewhat comparable (27\% for low income vs. $24 \%$ for high-income parents).

The best government estimate we have for comparison with the GSS data is a survey of licensed child care operators conducted in 2015 by the Ontario government (Ontario 
Table 3 Ontario child care usage from the GSS and revised estimates based on 2015 Ontario survey of HCC agencies

\begin{tabular}{|c|c|c|c|c|c|c|}
\hline & \multicolumn{3}{|c|}{ GSS results } & \multicolumn{3}{|c|}{$\begin{array}{l}\text { Revised estimates based on } 2015 \\
\text { Ontario survey of HCC agencies }\end{array}$} \\
\hline & Children & $\begin{array}{l}\text { Regular } \\
\text { users (\%) }\end{array}$ & $\begin{array}{l}\text { Within HCC } \\
\text { category (\%) }\end{array}$ & Children & $\begin{array}{l}\text { Regular } \\
\text { users (\%) }\end{array}$ & $\begin{array}{l}\text { Within } \mathrm{HCC} \\
\text { category (\%) }\end{array}$ \\
\hline Use regularly & 424,000 & 100 & & 424,000 & 100 & \\
\hline Center-based & 218,000 & 51 & & 218,000 & 51 & \\
\hline HCC-licensed & 65,000 & 15 & 32 & 11,000 & 3 & 5 \\
\hline \multicolumn{7}{|c|}{ Different forms of unlicensed care } \\
\hline Care by relative & 64,000 & 15 & 31 & 64,000 & 15 & 31 \\
\hline Out of home & 38,000 & 9 & 18 & 38,000 & 9 & 18 \\
\hline In child's home & 26,000 & 6 & 13 & 26,000 & 6 & 13 \\
\hline Care by stranger & 77,000 & 18 & 37 & 131,000 & 31 & 64 \\
\hline Out of home & 42,000 & 10 & 20 & 96,000 & 23 & 47 \\
\hline In child's home & 35,000 & 8 & 17 & 35,000 & 8 & 17 \\
\hline Licensed and unlicensed HCC & 107,000 & 25 & 52 & 107,000 & 25 & 52 \\
\hline Care by relative or nanny & 99,000 & 23 & 48 & 99,000 & 23 & 48 \\
\hline
\end{tabular}

Ministry of Education 2015). In that survey, HCC agencies reported enrollment in licensed HCC spaces broken down by children's age groups.

A total 12,374 children were classified in the age groups below the school entry. However, their age grouping includes an "infant" category of children between the ages of 0 and 18 months with a total count of 2987 infants enrolled in licensed HCC. Our sample from the GSS includes only infants who are older than 12 months of age. In an effort to increase the comparability of the two estimates, we corrected for this difference in our age categories by dropping half of the infant spaces (2987) reported in Ontario's survey to operations. This resulted in a rounded estimate of 11,000 spaces in Licensed HCC for children meeting our criteria of being older than 12 month and not yet in school. This number is far exceeded by the 65,000 children whose parents reported that they attended a Licensed HCC provider in Ontario based on the GSS.

\section{Discussion}

Nearly, one quarter of full-time working parents in our sample report that they do not use any type of child care on a regular basis. Full-time working parents reported that just over half of all children in these families are in licensed child care, and almost $23 \%$ were reported to be in some form of unlicensed care (see Fig. 1b). In the families that reported using child care on a regular basis, just over $70 \%$ reported using licensed child care, both center and HCC. Of the $30 \%$ who reported that they used some form unlicensed, nonparental care, $42 \%$ of children in this sample were cared for by relatives, while $21 \%$ were cared for by a stranger in their own home. Finally, approximately $38 \%$ of children of fulltime working parents who used ECEC on a regular basis were cared for by strangers outside the child's home.

In general, higher-income, better educated, working parents with fewer young children are in licensed care, compared to families who use no care at all. The pattern of results is similar when we compare parents whose children are in unlicensed care vs. 
no care at all. In addition, parents with irregular work schedules are more likely to place their children in unlicensed care or to have no care at all.

Analysis of child care utilization across different regions of Canada revealed a highly variable landscape. Notably Quebec, with its very different policies and government investments in ECEC services, is an outlier in many respects including high rates of utilization of ECEC services but low rates of use of unlicensed care. When Quebec's data is removed from the rest of Canada, utilization patterns in Ontario drive the pattern of results for the rest of the country. Ontario usage patterns drive those of Canada as a whole, at least to some extent, because it is so large. We cannot disaggregate data to the provincial level because of Statistics Canada data restrictions but Table 2 provides a breakdown by region. These figures highlight how policy interventions such as those implemented by the Quebec government can shift usage patterns. A large proportion of Quebec parents-62\%-report using licensed care (73\% of fulltime working parents); whereas in the rest of Canada, only 30\% report using licensed care. Only 9\% of Quebec parents use unlicensed care; whereas in the rest of Canada, $20 \%$ report using unlicensed care. At the same time, many fewer parents report using no care at all in Quebec when compared to parents in the rest of Canada where over half of parents reported having no care.

This highlights the need to consider policy options individually within each province. Regions are too different from one another to be grouped together and policy options must take their current status into account. With regards to the amount of time children spend in ECEC, Quebec is also an outlier with nearly two-thirds of children spending 30 or more hours per week in care $(69 \%$ in licensed and $64 \%$ in unlicensed care) compared to $53 \%$ in licensed care and $40 \%$ in unlicensed care in the rest of Canada.

In terms of who provides care in different regions in Canada, it is striking that Quebec has by far the lowest reliance on relatives for the provision of child care at $18 \%$, whereas about $30 \%$ of children in unlicensed care are being cared for by a relative in the rest of Canada.

While the available evidence shows that vulnerable children benefit most from access to high-quality center-based care (Bassok et al. 2016; Loeb et al. 2004), the GSS data reveal that across Canada, children who come from low-income families or have parents with less education are likely to be in care that has been found to be of lowest quality. Of those children in HCC, families with the very lowest incomes who receive provincial childcare subsidies are in all likelihood in licensed HCC. This is because in many parts of Canada subsidy dollars can only be spent in licensed child care. That means that low-income working parents without subsidies are likely to be the biggest users of unlicensed HCC. Ontario Government data highlight the prevalence of low-income families in the licensed HCC sector (Ontario Ministry of Education 2015, 2017a). In 2015, 66\% of children in licensed HCC were subsidized compared to only $28 \%$ in the centers. The difference between the two types increased even further by 2017 when $75 \%$ of children in licensed HCC were receiving a child care subsidy, compared to $30 \%$ in the licensed centers. Furthermore, the incomes of parents receiving a subsidy tend to be lower in licensed HCC than in center-based care. For example, examination of incomes of parents who receive a subsidy revealed that the "poorest of 
the poor" send their children to HCC ( $51 \%$ of subsidy recipients in HCC had incomes of $\$ 20,000$ or less, while only $18 \%$ of subsidy recipients had such low levels of income).

A surprising finding from the survey is the high percentage of working parents who report having no regular form of non-parental care. The GSS data reveal that, in Ontario, for example, $19 \%$ of families in which both parents work full-time (or one parent in the case of single parent households), representing 21.9\% (or approximately 79,000 ) of children between the ages of 12 month to school entry, report not using any form of non-parental ECEC services on a regular basis. These families are not regularly using grandparents or other relatives as that response is recorded separately in the GSS. Cost, availability, and a host of other factors may lead working parents to not use these services (Findlay 2019). Working parents may merely be "making do" by juggling their shifts or using occasional babysitting. We hypothesize that families feeling the biggest squeeze are those in the middle-income range who are not eligible for a subsidy, and for whom cost and lack of availability leave few options. In addition, securing ECEC services is very difficult for low-income families who are on waitlists for subsidies or are not able to find or afford a childcare space even with a subsidy. Clearly, more research is needed to understand why full-time working parents are not utilizing ECEC services and what the consequences are to children and families of being in this situation.

The results reported here suggest that irregular working hours, which $44 \%$ of families in our sample experienced, may act as a barrier to accessing any kind of regulated care (see Fig. 2). Research in the US (Han 2004) reveals that parents with previously nonstandard work schedules will switch from informal care to a regulated arrangement when their work schedules permit utilization of such care. Furthermore, having no child care is associated with lower incomes as families with above median income are far less likely to report having no care compared to families with income below the median. For example, in Ontario, 34\% of low-income parents report having no child vs. $15 \%$ of highincome parents. Together, these results strongly suggest that, for the most part, the use of parent-only childcare is a function of necessity rather than parental preference.

In $\mathrm{BC}$, the combination of high fees and capping of subsidies substantially below the full fee costs likely explains the high use of unlicensed HCC (32\%) as well as the high proportion of children of working parents without childcare (37\%). In contrast, the data from Quebec where ECEC services are much more affordable, ${ }^{2}$ suggest that, when given the option, working families prefer accessing licensed ECEC services. Specifically, the GSS data from 2011 reveal that less than 13\% of children in some form of regular childcare arrangement in Quebec were found in unlicensed care, as opposed to almost 46\% in Ontario. This suggests that fee subsidies enabled parents to move away from using unlicensed care. More recent data are needed to examine whether changes in the tax system allowing families to claim reimbursement for cost of care in the unlicensed HCC sector (Friendly et al. 2015) will lead to increases in parent utilization of such services in Quebec. Furthermore, it is important to note that while compared to the rest of Canada, more children of working parents in Quebec are in some form of non-parental care on a regular basis, there is a segment of families in Quebec who choose to arrange their work

2 The Government of Quebec introduced $\$ 5.00$ per day childcare in 1997 , with the fee subsidy gradually increasing over time to $\$ 7.00$, then $\$ 7.30$ and then a sliding fee scale in 2014 (Friendly et al. 2015). 
schedules in ways that enable them to accommodate all of their childcare needs within the family unit.

We speculate that the discrepancy between the number of available licensed HCC spaces reported by the Ontario government and parents in the GSS is due, at least in part, to the lack of clarity of the survey questions and variety of definitions provincial officials employ. It is possible that for various self-presentation and other issues, parents do not want to identify as sending their child to an unlicensed HCC provider. While the GSS data do not allow us to disentangle the reason for this misreporting it does suggest that at least some parents mistakenly think that their children attend licensed HCC when in fact they are in unlicensed HCC. This raises big concerns, especially around any reliance on parents as informed consumers of early childhood services.

Past governments, including Ontario's, have shied away from increasing oversight of the unlicensed sector due to various issues such as concerns about reduced access and am emphasis on enabling parent choice (White et al. 2018). Yet, we know very little about the actual factors that Canadian parents consider in weighing their childcare options (Gamble et al. 2009), including whether they will choose unlicensed care when licensed care options are available. Meanwhile, allowing unlicensed childcare to continue at least, in part, based on what appears to be a mistaken assumption that parents are free and informed consumers of childcare services, is problematic to say the least.

Several issues need to be considered with regard to the estimates from the Ontario government's survey of licensed child care operators. First, some HCC providers may take "private" clients in addition to those provided by the licensed HCC agencies; in those cases, the agencies would not necessarily include these children in the counts provided to the government. Second, a licensed provider may also be a relative of the child creating further confusion, especially if little or no payment for care is made. Third, the regulated capacity of a home does not prevent sharing of spaces between different families as in the case where one child comes in the morning and another one in the afternoon. Together, these create further ambiguity in available utilization estimates.

\section{Limitations of the current study}

While the GSS provides an important lens into ECEC utilization across Canada, it has several limitations. First, it uses the same terminology across the country in the survey questions posed, even though, as mentioned above, terminology varies across the country. Second, the GSS relies on parents' understanding of the care services they use; yet, we know from comparing survey responses to the number of licensed HCC spaces in Ontario that parents misreport whether their HCC provider is licensed. One possible source of confusion is the lack of differentiation between "regulation" and "licensing", even unlicensed HCC, is subject to at least minimal regulations regarding the maximum number of children for whom care can be provided legally at any one time.

In addition, due to confidentiality concerns caused by small sample sizes in the GSS, we were not always able provide the data by province or by forms of care and can only report national aggregates or information for Ontario only. The low usage rates of informal care in Quebec means that the sample size for Quebec was too low to reliably classify the unlicensed care into the four types. That necessitated presenting the data for regions as either "who provides care" or "where care is provided". Finally, 
the GSS does not shed light on why parents make some of the choices they make. Finally, increasing divergence in provincial policy and affordability initiatives represents a challenge for a national level survey, including the GSS, to accurately capture the changing nature of ECEC. Despite these limitations, the GSS data provide a useful source of parents understanding of their utilization of ECEC services.

\section{Conclusion and directions for future research}

Our findings reveal a number of issues that raise concerns about child care utilization patterns across the country. One is the high rates of working parents who report no child care at all, a situation that for many families is likely to be very stressful. Another is parents' over-reporting of children in licensed HCC. Parents' lack of accurate responses regarding basic information about their child's care arrangement suggests that parents should not be considered gatekeepers of quality, but rather that government has a key role to play in the licensing, support and oversight of ECEC services. However, more research is clearly needed to get information regarding parents' knowledge and preferences. The variability in the types of care used across different regions in Canada highlights the need for data, research and policy development at a regional level where the ECEC landscape can look quite different. While a broad strokes picture can be gleaned from national level surveys like the GSS, more nuanced and timely data are required to support provinces in their ongoing efforts to improve access to quality early learning and care for all children in their jurisdictions.

Finally, the finding that low-income, less educated parents use unlicensed HCC at higher rates than higher-income, better educated families raises important equity concerns about ECEC utilization in Canada. The existing regulatory system magnifies that gap in allowing a portion of HCC to remain unlicensed and largely unregulated. Any policy interventions to expand the HCC supply need to recognize the inequities that can be exacerbated without greater regulatory intervention.

Governments across the country are struggling with the need to increase the availability of ECEC services. Across the partisan political spectrum, HCC has emerged as a key part of such plans. For example, in Ontario, the previous Liberal government proposed to increase access to licensed childcare services by, at least in part, increasing the role of HCC, including base funding of home childcare agencies (Ontario Ministry of Education 2017b). Expansion of Ontario's licensed HCC may appear to the government to be the fastest way to meet the demand for care. More recently, the new Progressive Conservative government proposed in its election platform to introduce a refundable tax credit that could be applied toward ECEC costs in the licensed and unlicensed sectors. However, there is no evidence that, on the whole, unlicensed HCC is perceived as a desirable choice by parents. In fact, evidence from Quebec suggests that given the choice, parents use licensed care. All families, including the lowest income families, deserve access to good-quality ECEC services. To level the playing field, governments need to ensure quality of care through research, licensing, support and oversight. 


\section{Authors' contributions}

The authors are responsible for the reported research. All of the authors have participated in conceptualization and design, analysis and interpretation of data and in drafting or revising of the manuscript. All authors read and approved the final manuscript.

\section{Funding}

This research was carried without external funding.

\section{Availability of data and materials}

The data used in this study have been generated from the Cycle 25 of General Social Survey of Canada (GSS). The analytical file can be accessed through the Statistics Canada Research Data Centres, subject to constraints for protection of individual information.

\section{Competing interests}

The authors declare that they have no competing interests.

\section{Author details}

${ }^{1}$ Applied Psychology and Human Development, Ontario Institute for Studies in Education/University of Toronto, Toronto, Canada. ${ }^{2}$ Applied Psychology and Human Development, Ontario Institute for Studies in Education/University of Toronto, Room 9-231, 252 Bloor Street West, Toronto, ON M5S 1V6, Canada. ${ }^{3}$ Political Science and Munk School of Global Affairs and Public Policy, University of Toronto, 100 St. George Street Room 3061, Toronto, ON M5S 3G3, Canada.

Received: 8 January 2019 Accepted: 12 October 2019

\section{Published online: 25 October 2019}

\section{References}

Bassok, D., Fitzpatrick, M., Greenberg, E., \& Loeb, S. (2016). Within- and between-sector quality differences in early childhood education and care. Child Development, 87(5), 1627-1645. https://doi.org/10.1111/cdev.12551.

Bigras, N., Bouchard, C., Cantin, G., Brunson, L., Coutu, S., Lemay, L., et al. (2010). A comparative study of structural and process quality in center-based and family-based child care services. Child \& Youth Care Forum, 39(3), 129-150.

Blank, R. M. (2000). When can public policy makers rely on private markets? The effective provision of social services. The Economic Journal, 110(462), 34-49. https://doi.org/10.1111/1468-0297.00519.

Blau, D. M. (2007). Unintended consequences of child care regulations. Labour Economics, 14(3), 513-538. https://doi. org/10.1016/j.labeco.2006.01.003.

Brunsek, A., Perlman, M., Falenchuk, O., McMullen, E., Fletcher, B., \& Shah, P. S. (2017). The relationship between the Early Childhood Environment Rating Scale and its revised form and child outcomes: A systematic review and meta-analysis. PLoS ONE, 12(6), e0178512. https://doi.org/10.1371/journal.pone.0178512.

Burchinal, M. (2018). Measuring early care and education quality. Child Development Perspectives, 12(1), 3-9. https://doi. org/10.1111/cdep.12260.

Burchinal, M., Magnuson, K., Powell, D., \& Hong, S. S. (2015). Early childcare and education. In M. H. Bornstein, T. Leventhal, \& R. M. Lerner (Eds.), Handbook of child psychology and developmental science (pp. 1-45). Hoboken: Wiley.

Canada, E., \& S. D. (2017, August 23). Canada-Ontario early learning and child care agreement [Navigation page-partnering and collaborative arrangement profile]. Retrieved April 30, 2018, from Aem website https://www.canada.ca/en/ early-learning-child-care-agreement/agreements-provinces-territories/ontario.html.

CBC. (2013, February 22). Who's watching the kids? In Marketplace. Retrieved from http://www.cbc.ca/marketplace/episo des/2012-2013/whos-watching-the-kids.

Cleveland, G., Forer, B., Hyatt, D., Japel, C., \& Krashinsky, M. (2008). New evidence about child care in canada: Use patterns, affordability and quality. Retrieved from http://archive.irpp.org/choices/archive/vol14no12.pdf.

Cloney, D., Cleveland, G., Hattie, J., \& Tayler, C. (2016). Variations in the availability and quality of early childhood education and care by socioeconomic status of neighborhoods. Early Education and Development, 27(3), 384-401. https://doi. org/10.1080/10409289.2015.1076674.

Côté, S. M., Borge, A. I., Geoffroy, M.-C., Rutter, M., \& Tremblay, R. E. (2008). Nonmaternal care in infancy and emotional/ behavioral difficulties at 4 years old: Moderation by family risk characteristics. Developmental Psychology, 44(1), 155-168. https://doi.org/10.1037/0012-1649.44.1.155.

Davis, E. E., Carlin, C. S., Krafft, C., \& Tout, K. (2014). Time for a change? Predictors of child care changes by low-income families. Journal of Children and Poverty, 20(1), 21-45. https://doi.org/10.1080/10796126.2014.894003.

Debacker, M. (2008). Care strategies among high- and low-skilled mothers: A world of difference? Work, Employment \& Society, 22(3), 527-545. https://doi.org/10.1177/0950017008093476.

Findlay, L. (2019). Early learning and child care for children aged 0 to 5 years: A provincial/territorial portraitz. Ottawa: Statistics Canada. (No. Report No. 099. Cat No. 11-626-X).

Forry, N., Isner, T. K., Daneri, M. P., \& Tout, K. (2014). Child care decision making: Understanding priorities and processes used by low-income families in Minnesota. Early Education and Development, 25(7), 995-1015. https://doi. org/10.1080/10409289.2014.893758.

Friendly, M., Grady, B., Macdonald, L., \& Forer, B. (2015). Early childhood education and care in Canada 2014. Retrieved from Childcare Resource and Research Unit website: http://childcarecanada.org/publications/ecec-canada/16/03/early -childhood-education-and-care-canada-2014.

Friendly, M., Larsen, E., Feltham, L.E., Grady, B., Forer, B., \& Jones, M. (2018). Early childhood education and care in Canada 2016. Toronto: Childcare Resource and Research Unit.

Gable, S., \& Halliburton, A. (2003). Barriers to child care provider's professional development. Child and Youth Care Forum, 32(3). 
Gamble, W. C., Ewing, A. R., \& Wilhlem, M. S. (2009). Parental perceptions of characteristics of non-parental child care: Belief dimensions, family and child correlates. Journal of Child and Family Studies, 18(1), 70-82. https://doi. org/10.1007/s10826-008-9208-z.

Gingras, L. (2012). Quelques caractéristiques associées à l'utilisation des services de garde à contribution réduite dans la dernière décennie. Portraits \& Trajectoires, (13). Retrieved from http://www.stat.gouv.qc.ca/statistiques/sante/bulle tins/portrait-201203.pdf.

Goelman, H., \& Pence, A. (1988). Children in three types of day care: Daily experiences, quality of care and developmental outcomes. Early Child Development and Care, 33(1), 67-76. https://doi.org/10.1080/0300443880330105.

Goelman, H., Pence, A., Lero, D., Brockman, L., Glick, N., \& Berkowitz, J. (1993). Canadian National Child Care Study: Where are the Children?: An overview of child care arrangements in Canada. Ottawa: Statistics Canada.

Haeck, C., Lefebvre, P., \& Merrigan, P. (2015). Canadian evidence on ten years of universal preschool policies: The good and the bad. Labour Economics, 36, 137-157. https://doi.org/10.1016/j.labeco.2015.05.002.

Han, W.-J. (2004). Nonstandard work schedules and child care decisions: Evidence from the NICHD Study of Early Child Care. Early Childhood Research Quarterly, 19(2), 231-256. https://doi.org/10.1016/j.ecresq.2004.04.003.

Harms, T., Clifford, R., \& Cryer, D. (1998). Early childhood environment rating scale-revised. New York: Teachers College Press.

Howe, N., Jacobs, E., Vukelich, G., \& Recchia, H. (2013). Canadian parents'knowledge and satisfaction regarding their child's day-care experience. Journal of Early Childhood Research, 11(2), 133-148. https://doi.org/10.1177/1476718X12 466214.

Japel, C., Tremblay, R. E., \& Côté, S. M. (2005). Quality Counts! Assessing the quality of daycare services based on the Quebec longitudinal study of child development. IRPP Choices, 11(5). Retrieved from http://www.irpp.org/choices/ archive/vol11 no5.pdf.

Kamerman, S. B., \& Gatenio-Gabel, S. (2007). Early childhood education and care in the United States: An overview of the current policy picture. International Journal of Child Care and Education Policy, 1(1), 23-34. https://doi. org/10.1007/2288-6729-1-1-23.

Kohen, D., Dahinten, V. S., Khan, S., \& Hertzman, C. (2008). Child care in Quebec: Access to a universal program. Canadian Journal of Public Health/Revue Canadienne de Sante'e Publique, 99(6), 451-455. Retrieved from http://www.jstor.org/ stable/41995150.

Kontos, S., Howes, C., Shinn, M., \& Galinsky, E. (1995). Quality in family child care and relative care. New York: Teachers College Press.

Laurin, J. C., Geoffroy, M.-C., Boivin, M., Japel, C., Raynault, M.-F., Tremblay, R. E., et al. (2015). Child care services, socioeconomic inequalities, and academic performance. Pediatrics, 136(6), 1112-1124. https://doi.org/10.1542/ peds.2015-0419.

Lefebvre, P., Merrigan, P. and Roy-Desrosiers, F., 2012. Quebec's childcare universal low fees policy 10 years after: Effects, costs and benefits. Centre interuniversitaire sur le risque, les politiques économiques et l'emploi.

Lehrer, J. S., Lemay, L., \& Bigras, N. (2015). parental perceptions of child care quality in centre-based and home-based settings: Associations with external quality ratings. International Journal of Early Childhood, 47(3), 481-497. https://doi. org/10.1007/s13158-015-0147-8.

Loeb, S., Fuller, B., Kagan, S. L., \& Carrol, B. (2004). Child care in poor communities: Early learning effects of type, quality, and stability. Child Development, 75(1), 47-65. Retrieved from http://www.jstor.org.myaccess.library.utoronto.ca/stabl e/3696565.

Magnuson, K. A., Ruhm, C., \& Waldfogel, J. (2007). The persistence of preschool effects: Do subsequent classroom experiences matter? Early Childhood Research Quarterly, 22(1), 18-38. https://doi.org/10.1016/j.ecresq.2006.10.002.

Malik, R., \& Hamm, K. (2017). Mapping America's child care deserts. Washington: Center for American Progress.

McCartney, K., Dearing, E., Taylor, B. A., \& Bub, K. L. (2007). Quality child care supports the achievement of low-income children: Direct and indirect pathways through caregiving and the home environment. Journal of Applied Developmental Psychology, 28(5-6), 411-426. Retrieved from http://resolver.scholarsportal.info/resolve/01933973/v28i5 $-6 / 411$ qccstatcathe.

Mocan, N. (2007). Can consumers detect lemons? An empirical analysis of information asymmetry in the market for child care. Journal of Population Economics, 20(4), 743-780. Retrieved from http://resolver.scholarsportal.info/resol ve/09331433/v20i0004/743_ccdlaeitmfcc.

Ontario Ministry of Education. (2015). 2015 Licensed child care operators survey report. Retrieved from http://www.edu.gov. on.ca/childcare/2015LicensedChildCareOperatorsReport.html.

Ontario Ministry of Education. (2017a). 2017 Licensed child care operators survey report. Retrieved from Government of Ontario website: http://www.edu.gov.on.ca/childcare/2017LicensedChildCareOperatorsReport.html.

Ontario Ministry of Education. (2017b, June 6). Ontario's renewed early years and child care policy framework. Retrieved from http://www.edu.gov.on.ca/childcare/renewed_early_years_child_care_policy_framework_en.pdf.

Ontario Ombudsman. (2014). Careless about child care [Ombudsman Report]. Retrieved from https://ombudsman.on.ca/ Files/sitemedia/Documents/CarelessAboutChildCareEN_1.pdf.

Pavolini, E., \& Van Lancker, W. (2018). The Matthew effect in childcare use: A matter of policies or preferences? Journal of European Public Policy, 25(6), 878-893. https://doi.org/10.1080/13501763.2017.1401108.

Perlman, M., Varmuza, P., \& White, L. A. (2017). Path-dependent policy making and unlicensed childcare: Lessons from Ontario. In S. Prentice (Ed.), Caring for children: Social movements and public policy in Canada. Vancouver: UBC Press.

Phillips, D. A., Lipsey, M. W., Dodge, K. A., Haskins, R., Bassok, D., Burchinal, M. R., ... Weiland, C. (2017). The current state of scientific knowledge on pre-kindergarten effects. Washington, DC. Retrieved April 18, 2017, from https://www.brook ings.edu/wp-content/uploads/2017/04/consensus-statement_final.pdf.

Porter, T., Paulsell, D., Del Grosso, P., Avellar, S., Hass, R., \& Vuong, L. (2010). A review of the literature on home-based child care: Implications for future directions. Princeton: Mathematica Policy Research.

Raikes, H. A., Raikes, H. H., \& Wilcox, B. (2005). Regulation, subsidy receipt and provider characteristics: What predicts quality in child care homes? Early Childhood Research Quarterly, 20(2), 164-184. https://doi.org/10.1016/j.ecres q.2005.04.006. 
Sandstrom, H., \& Chaudry, A. (2012). 'You have to choose your childcare to fit your work': Childcare decision-making among low-income working families. Journal of Children and Poverty, 18(2), 89-119. https://doi.org/10.1080/10796 126.2012.710480.

Sinha, M. (2014). Child care in Canada 2014. Retrieved from Statistics Canada, Social and Aboriginal Statistics Division website: http://www.deslibris.ca/ID/244808.

Stata Statistical Software: Release 15. (2017). College Station, TX: StataCorp LP.

Statistics Canada. (2011). General Social Survey, Cycle 25; Family (analytic file) [Database]. Statistics Canada, Ottawa, Ontario [producer and distributor].

Torquati, J. C., Raikes, H. H., Huddleston-Casas, C. A., Bovaird, J. A., \& Harris, B. A. (2011). Family income, parent education, and perceived constraints as predictors of observed program quality and parent rated program quality. Early Childhood Research Quarterly, 26(4), 453-464. Retrieved from http://resolver.scholarsportal.info/resolve/08852006/v26i0 004/453_fipeapqaprpq.

Van Lancker, W., \& Ghysels, J. (2016). Explaining patterns of inequality in childcare service use across 31 developed economies: A welfare state perspective. International Journal of Comparative Sociology, 57(5), 310-337. https://doi. org/10.1177/0020715216674252.

Walker, J. R. (1992). New evidence on the supply of child care: A statistical portrait of family providers and an analysis of their fees. The Journal of Human Resources, 27(1), 40. https://doi.org/10.2307/145912.

Weiland, C., \& Yoshikawa, H. (2013). Impacts of a prekindergarten program on children's mathematics, language, literacy, executive function, and emotional skills. Child Development, 84(6), 2112-2130.

White, L. A., Perlman, M., Davidson, A., \& Rayment, E. (2019). Risk perception, regulation, and unlicensed child care: Lessons from Ontario, Canada. Journal of Risk Research, 22(7), 878-896.

\section{Publisher's Note}

Springer Nature remains neutral with regard to jurisdictional claims in published maps and institutional affiliations.

\section{Submit your manuscript to a SpringerOpen ${ }^{\circ}$ journal and benefit from:}

Convenient online submission

Rigorous peer review

- Open access: articles freely available online

- High visibility within the field

Retaining the copyright to your article

Submit your next manuscript at $\boldsymbol{\Delta}$ springeropen.com 